\title{
Contabilidade
}

\section{PADRÃO DE ESPECIALIZAÇÃO DO COMÉRCIO INTERNACIONAL DO SETOR FLORESTAL BRASILEIRO (1999 - 2015)}

\author{
Nome \\ Mygre Lopes da Silva \\ Instituição/Afiliação \\ Professora da Universidade Federal do Pampa (Unipampa). \\ País \\ Brasil \\ Resumo da \\ Biografia \\ Bachareal em Ciências Econômicas, mestre e doutora em Administração pela \\ Universidade Federal de Santa Maria (UFSM). \\ Contato principal para correspondência. \\ Nome \\ Instituição/Afiliação \\ País \\ Resumo da \\ Biografia \\ Nome \\ Instituição/Afiliação \\ País \\ Resumo da \\ Biografia \\ Carla Rosane da Costa Sccott \\ Professora do Colégio Politécnico da UFSM. \\ Brasil \\ Doutoranda em Extensão Rural UFSM. Graduação em Ciências Contábeis - \\ UNIFRA. Mestrado em Engenharia de Produção - UFSM, Licenciatura Pedagógica \\ para Educação Básica, Técnica e Tecnológica - UFSM. \\ Daniel Arruda Coronel \\ Professor e Diretor da Editora da UFSM. \\ Brasil \\ Doutor em Economia Aplicada pela Universidade Federal de Viçosa (UFV); mestre \\ em Agronegócios pela Universidade Federal do Rio Grande do Sul (UFRGS), \\ bacharel em Administração pela Universidade do Vale do Rio dos Sinos \\ (UNISINOS) (CRA-RS, Registro: 047444) e em Ciências Econômicas pela UFSM \\ (CORECON-RS, Registro: 7811).
}

\section{RESUMO:}

Este trabalho buscou analisar o padrão de especialização do comércio internacional do setor florestal brasileiro, identificando os setores produtivos mais dinâmicos, no período entre 1999 a 2015. Para isso, calcularam-se os indicadores de Taxa de Cobertura das Importações (TC), de Comércio Intraindústria (CII) e de Concentração Setorial das Exportações (ICS). Os dados foram coletados no Sistema de Análise de Informações do Comércio Exterior (Alice Web). Os resultados indicaram que o Brasil apresenta vantagens comparativas nos setores de madeira, carvão vegetal e obras de madeira e pastas de madeira ou de outras matérias fibrosas celulósicas, papel ou cartão para reciclar. A maior parte dos setores do mercado florestal apresenta comércio interindustrial, exceto borracha e suas obras e papel e cartão, obras de pasta de celulose, de papel ou de cartão. Além disso, o setor florestal brasileiro apresenta um padrão de concentração uniforme.

Palavras-chave: Exportações; Brasil; Setor Florestal.

\section{INTRODUÇÃO}

O comércio internacional pode ser conceituado pela troca, entre seus territórios, de determinados bens e serviços, dos quais as empresas dispõem. Neste sentido, o processo de globalização das economias propiciou a comercialização entre os países, podendo promover maior eficiência na alocação dos recursos, no pleno emprego, no crescimento e na distribuição internacional da renda, condições estas que ampliam o bem-estar das sociedades (PETRAUSKI ET AL., 2012). 
Cruvinel (2009) salienta que, no Brasil, o comércio internacional, principalmente de produtos do agronegócio, é importante para a geração de divisas, sendo uma atividade responsável por manter o equilíbrio da balança comercial. Neste contexto, é possível observar que, dentre os produtos do agronegócio, considerando as commodities mais tradicionais, a borracha, a madeira, o mobiliário e o papel, são os produtos florestais que se destacam com bastante propriedade.

O território brasileiro possui condições edafoclimáticas bastante favoráveis para a regeneração florestal, proporcionando ao país fortes vantagens comparativas para esta atividade, refletindo a relevância socioeconômica e ambiental deste setor, bem como a sua extrema importância para o desenvolvimento econômico brasileiro.

Nesse sentido, a relevância deste estudo pode ser ressaltada por diversos aspectos. Dentre eles, destaca-se que, das exportações totais brasileiras, cerca de $8,95 \%$ eram de produtos florestais, em 1999, passando para 6,06\%, em 2015 (SISTEMA DE ANÁLISE DAS INFORMAÇÕES DE COMÉRCIO EXTERIOR - ALICE WEB, 2016). Além disso, o Brasil possui a segunda maior cobertura florestal do mundo, estando entre os principais detentores de recursos naturais (ASSOCIAÇÃO BRASILEIRA DA INDÚSTRIA DE MADEIRA PROCESSADA MECANICAMENTE - ABIMCI, 2014).

Outro aspecto que merece destaque é que o setor florestal representa cerca de 3,5\% do PIB Brasil, responsável também por altos índices de empregabilidade, evidenciando-se também pela sua representatividade como fornecedor de matéria-prima para a indústria de transformação (INSTITUTO DE PESQUISAS E ESTUDOS FLORESTAIS - IPEF, 2016).

Por fim, este estudo justifica-se também, pois, apesar do setor possuir grande representatividade no comércio mundial, Petrouski et al. (2012) salientam que ele ainda carece de necessidades estratégicas para o aumento da competitividade no exterior, podendo promover maiores possibilidades de ganhos para o Brasil.

Neste contexto, a problemática de pesquisa que norteou o estudo foi: "Qual o padrão de especialização do comércio internacional do setor florestal brasileiro, no período entre 1999 a 2015?’. Tem como objetivo geral analisar o padrão de especialização das exportações florestais brasileiras, no período entre 1999 a 2015.

Para alcançar o objetivo proposto, foram utilizados três indicadores de comércio internacional, sendo eles: indicador de Taxa de Cobertura das Importações (TC), Comércio Intraindústria (CII) e Concentração Setorial das Exportações (ICS).

É preciso também ressaltar a escassez de pesquisas no setor florestal brasileiro, pois a maioria da literatura aborda análises setoriais e locais, por meio de análise qualitativa, podendo ser mencionados os estudos dos seguintes autores: Juvenal e Mattos (2002), Carvalho, Soares e Valverde, (2005) e Lentini et al. (2005), e também estudos que abordam outros métodos quantitativos, os quais não se reportam aos indicadores de comércio internacional propostos neste estudo, como as pesquisas de Noce et al. (2003), Noce et al. (2005), Valverde et al. (2005b), Valverde, Soares e Silva (2006) e Souza et al. (2010).

Além desta introdução, o artigo está organizado da seguinte forma: a seção 2 apresenta a estrutura das exportações brasileiras do setor florestal; na seção 3, é apresentada a metodologia; na seção 4, encontram-se os resultados e a discussão; e, por fim, na seção 5, são apresentadas as considerações finais.

\section{A ESTRUTURA DAS EXPORTAÇÕES BRASILEIRAS DO SETOR FLORESTAL}

Na percepção de Sousa et al. (2010), o setor florestal destacou-se, no Brasil, a partir, da aprovação da legislação de incentivos fiscais ao reflorestamento em 1966, a qual 
possibilitou às empresas deste setor abaterem até $50 \%$ (por cento) do valor do imposto de renda, para serem aplicados em projetos florestais.

Desse modo, como já mencionado, as exportações brasileiras de produtos florestais chegaram a representar cerca de 6,06\% das exportações brasileiras totais em 2015. Já no que tange às importações brasileiras, estas representaram cerca de $2,69 \%$ do total das importações do Brasil, também em 2015 (ALICE WEB, 2016).

A partir dessas políticas de incentivo, o setor brasileiro florestal tornou-se superavitário A Figura 1, a seguir, ilustra essa quantificação monetária, relaçionando as exportações com as importações no período de 1999 a 2015.

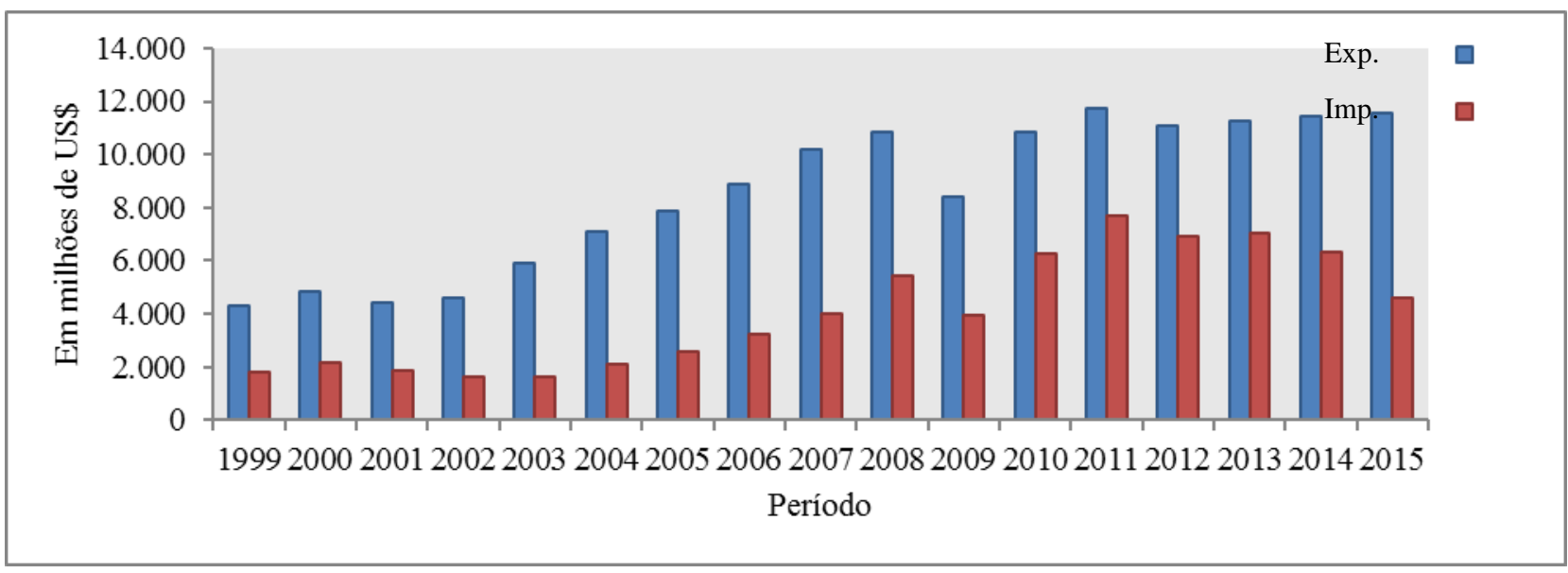

Figura 1 - Exportações (X) e Importações (M) florestais brasileiras (em milhões US\$ FOB) Fonte: Elaboração própria a partir dos dados do Sistema Alice Web.

De acordo com a figura apresentada anteriormente, é possível observar que, no período de 1999 a 2015, as exportações cresceram de forma gradativa,e isto se tornou viável para a economia brasileira porque o Brasil inovou e buscou novas tecnologias, melhorou seus produtos e serviços, possibilitando a conquistas de novos mercados.

Entretanto, houve alguns decréscimos das exportações, principalmente em 2009. Para o Ministério do Desenvolvimento da Indústria e Comércio Exterior - MDIC (2015), essa queda pode ter sido ocasionada pela crise econômica mundial ocorrida em 2008, a qual afetou o comércio exterior, impactando na redução das exportações devido aos menores preços de exportação dos principais produtos do setor, refletindo em déficit na balança comercial.

Já na ótica de Petrauski et al. (2012), a queda nas exportações, em 2009, está relacionada a fatores como excessiva tributação, entraves burocráticos, taxas de juros incompatíveis, falta de recursos para investimentos, legislação equivocada, entre outros fatores que ainda limitam a competitividade do setor.

Quanto às importações, a Figura 1 aponta uma queda considerável também em 2009. Segundo estudos do Ministério do Desenvolvimento da Indústria e Comércio Exterior MDIC (2015), essa queda pode ter sido ocasionada pela contração na economia, isto é, uma limitação na capacidade de compra do Brasil, ocasionada pelos baixos investimentos do capital produtivo.

Nesse contexto, a Figura 2, a seguir, apresenta dados com relação às exportações brasileiras especificamente do setor florestal, no período de 1999 a 2015, abrangendo a indústria da borracha, da madeira, de mobiliário, de papel e gráfica. Com os dados expostos, observa-se que a indústria de celulose e de papel ganhou destaque, visto que o propósito dessas indústrias foi atingir fortemente o comércio exterior, buscando a competitividade frente aos grandes produtores dos países mais desenvolvidos. 


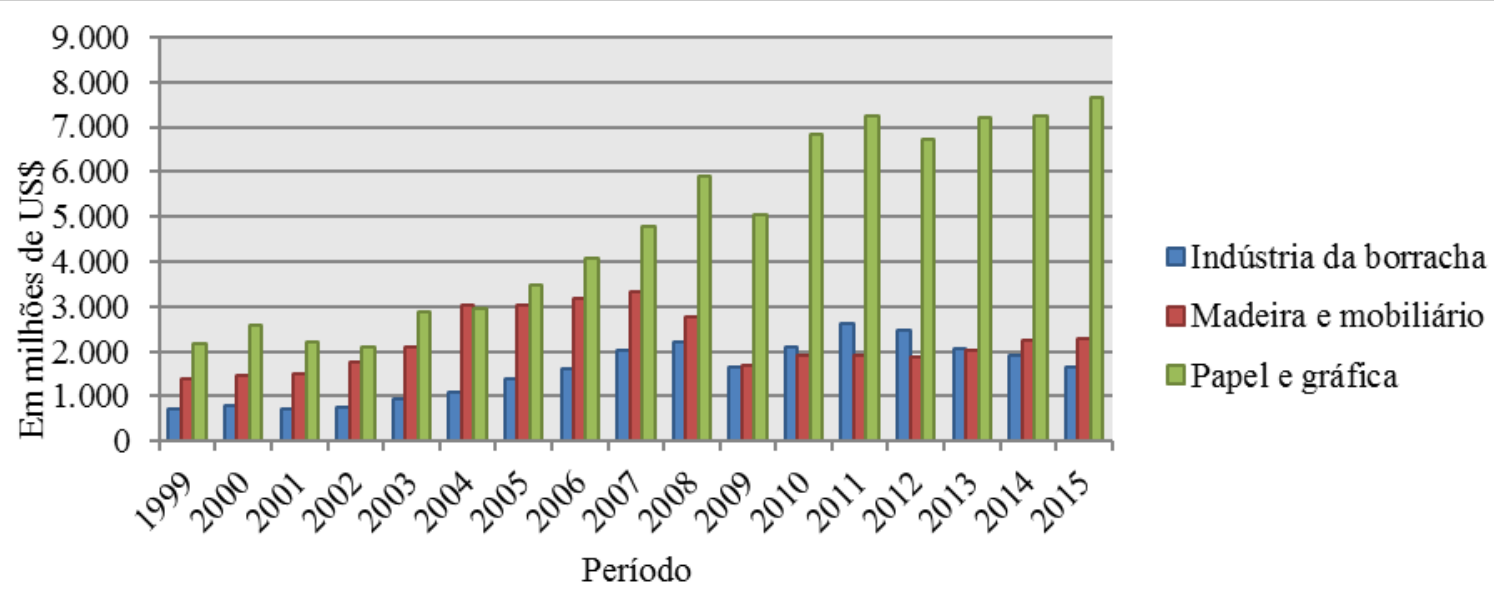

Figura 2 - Exportações brasileiras do setor florestal (em milhões US\$ FOB)

Fonte: Elaboração própria a partir dos dados do Sistema Alice Web.

Com base na Figura 2, é possível visualizar que a indústria de papel e gráfica contribuiu de forma relevante para o desenvolvimento do país, e isso se deve muito ao baixo custo de produção e à grande utilização de papel no mundo todo. Além disso, empresas brasileiras de celulose são competitivas devido à alta produtividade dos reflorestamentos, pois as condições climáticas possibilitam ciclos de crescimento rápido, de alta qualidade e de baixo custo de produção em relação aos outros países (IPEF, 2016).

Os principais importadores de produtos florestais brasileiros são a Argentina, a Alemanha e a China, os quais se destacam na importação de papel, compensados e celulose, respectivamente. Já os Estados Unidos importam principalmente painéis e madeira serrada. Isso porque a produção de florestas caracteriza-se por ser um investimento de longo prazo que exige consciência e diligência na política e no planejamento, mas, sobretudo, nas práticas de gestão, a fim de evitar impactos negativos, e o Brasil trabalha de forma bastante incisiva neste processo (ASSOCIAÇÃO BRASILEIRA DE PRODUTORES DE FLORESTAS PLANTADAS - ABRAF, 2013).

Dentre outros aspectos observados, constata-se que a principal lacuna do setor é a borracha natural, onde o país é deficitário, conforme a Figura 3, a seguir.

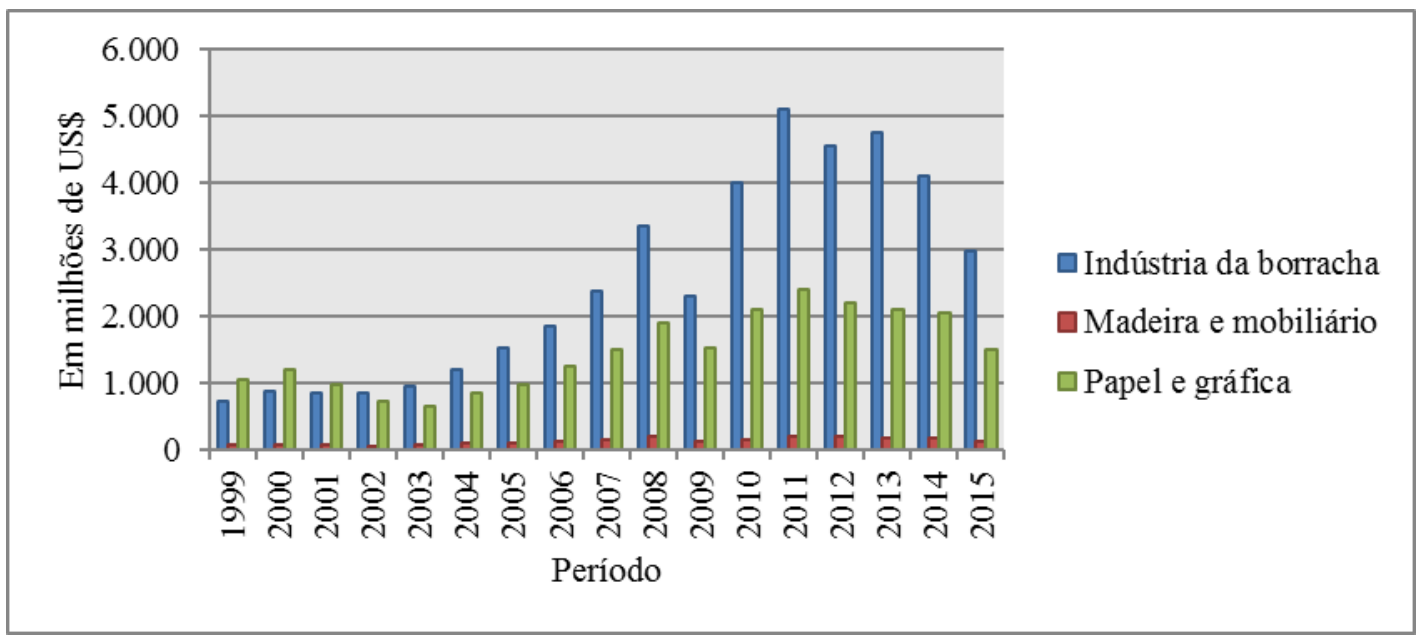

Figura 3 - Importações brasileiras do setor florestal (em milhões US\$ FOB)

Fonte: Elaboração própria a partir dos dados do Sistema Alice Web. 
A Figura 3 evidencia as importações brasileiras no setor de borracha, possuindo São Paulo como principal estado produtor, com cerca de $54 \%$ da produção nacional, o que ainda não é suficiente para atender a demanda, necessitando de mais investimentos neste segmento (IPEF, 2016).

De maneira complementar, é preciso analisar a estrutura das exportações do setor florestal brasileiro segundo grupos de produtos. De acordo com a Tabela 1, os produtos que obtiveram maior crescimento percentual na pauta exportadora brasileira, entre os anos de 1999 e 2015, foram os de pastas de madeira ou de outras matérias fibrosas celulósicas, papel ou cartão para reciclar $(349,27 \%)$; papel e cartão, obras de pasta de celulose, de papel ou de cartão (126,73\%); cortiça e suas obras (125,11\%); borracha e suas obras $(124,70 \%)$; e madeira, carvão vegetal e obras de madeira $(63,28 \%)$. 
Tabela 1 - Estrutura das exportações florestais brasileiras segundo grupos de produtos em (\%)

\begin{tabular}{|c|c|c|c|c|c|c|c|c|c|c|c|c|c|c|c|c|c|c|}
\hline Produtos/períodos & 1999 & 2000 & 2001 & 2002 & 2003 & 2004 & 2005 & 2006 & 2007 & 2008 & 2009 & 2010 & 2011 & 2012 & 2013 & 2014 & 2015 & $\begin{array}{c}\text { Taxa } \\
\text { de cresc. } \\
1999 \text { a } 2015\end{array}$ \\
\hline $\begin{array}{l}\text { Borracha e suas obras } \\
\text { Madeira, carvão } \\
\text { vegetal e obras de } \\
\text { madeira }\end{array}$ & 32,81 & 31,07 & 34,04 & 38,70 & 35,49 & 43,24 & 38,74 & 35,90 & 20,15 & 25,70 & 20,60 & 18,21 & 16,70 & 17,65 & 18,36 & 20,29 & 20,03 & 63,28 \\
\hline $\begin{array}{l}\text { Cortiça e suas obras } \\
\text { Obras de espartaria ou }\end{array}$ & 0,017 & 0,020 & 0,016 & 0,028 & 0,027 & 0,021 & 0,022 & 0,023 & 0,022 & 0,021 & 0,023 & 0,018 & 0,023 & 0,025 & 0,021 & 0,019 & 0,014 & 125,11 \\
\hline $\begin{array}{l}\text { cestaria } \\
\text { Pastas de madeira ou } \\
\text { de outras matérias } \\
\text { fibrosas celulósicas; } \\
\text { papel ou cartão para }\end{array}$ & 0,003 & 0,002 & 0,002 & 0,002 & 0,052 & 0,038 & 0,003 & 0,003 & 0,003 & 0,003 & 0,002 & 0,001 & 0,002 & 0,004 & 0,002 & 0,002 & 0,002 & 59,87 \\
\hline $\begin{array}{l}\text { reciclar } \\
\text { Papel e cartão; obras } \\
\text { de pasta de celulose, } \\
\text { de papel ou de cartão }\end{array}$ & 28,14 & 32,34 & 27,43 & 24,42 & 28,85 & 23,68 & 25,24 & 27,64 & 29,26 & 35,30 & 37,79 & 42,22 & 40,67 & 40,51 & 44,27 & 44,53 & 47,27 & 349,27 \\
\hline $\begin{array}{l}\text { Livros, jornais, } \\
\text { gravuras e outros } \\
\text { produtos de indústrias } \\
\text { gráficas } \\
\text { Total do setor }\end{array}$ & $\begin{array}{l}0,746 \\
\mathbf{1 0 0}\end{array}$ & $\begin{array}{l}0,621 \\
\mathbf{1 0 0}\end{array}$ & $\begin{array}{l}0,642 \\
\mathbf{1 0 0} \\
\end{array}$ & $\begin{array}{l}0,674 \\
\mathbf{1 0 0} \\
\end{array}$ & $\begin{array}{l}0,699 \\
\mathbf{1 0 0} \\
\end{array}$ & $\begin{array}{l}0,733 \\
\mathbf{1 0 0} \\
\end{array}$ & $\begin{array}{l}0,764 \\
\mathbf{1 0 0} \\
\end{array}$ & $\begin{array}{l}0,765 \\
\mathbf{1 0 0} \\
\end{array}$ & $\begin{array}{l}0,656 \\
\mathbf{1 0 0} \\
\end{array}$ & $\begin{array}{l}0,569 \\
\mathbf{1 0 0} \\
\end{array}$ & $\begin{array}{l}0,548 \\
\mathbf{1 0 0}\end{array}$ & $\begin{array}{l}0,477 \\
\mathbf{1 0 0}\end{array}$ & $\begin{array}{l}0,521 \\
100\end{array}$ & $\begin{array}{l}0,550 \\
\mathbf{1 0 0}\end{array}$ & $\begin{array}{l}0,344 \\
\mathbf{1 0 0}\end{array}$ & $\begin{array}{l}0,378 \\
\mathbf{1 0 0}\end{array}$ & $\begin{array}{l}0,360 \\
\mathbf{1 0 0} \\
\end{array}$ & $\begin{array}{c}29,09 \\
167,46\end{array}$ \\
\hline
\end{tabular}
Fonte: Elaboração própria a partir dos dados do Sistema Alice Web. 
A história da borracha natural, no Brasil, exerceu uma influência importante na situação do setor, apresentando a última exportação expressiva de borracha natural em 1947, devido à racionalização da heveicultura no Brasil, por parte do governo, criando uma barreira na produção brasileira. Nesse sentido, tem-se como obstáculo o consumo elevado de borracha no Brasil, a falta de incentivos fiscais e políticas de gestão adequadas para o incentivo desta produção, cuja demanda cresceu de forma expansiva, ocasionando a necessidade de elevada importação desta matéria-prima para atender ao mercado (INSTITUTO AGRONÔMICO DE CAMPINAS - IAC, 2016). Dessa forma, apresentam-se como os principais fornecedores de borracha natural para o Brasil a Tailândia e a Indonésia devido à alta produtividade desses países neste setor (CRUVINEL, 2009).

\section{MATERIAL E MÉTODOS}

Nesta seção, são apresentados os três indicadores utilizados, os quais têm por objetivo identificar o padrão de comércio florestal brasileiro.

O primeiro indicador é a taxa de cobertura das importações (TC), a qual indica quantas vezes o volume das exportações do setor i está cobrindo seu volume de importação. $\mathrm{O}$ índice é expresso através da Equação 1:

$$
T C_{i j}=\frac{X_{i j} / M_{i j}}{X_{i} / M_{i}}
$$

onde:

Xij representa as exportações do setor i do país j (BRA);

$\mathrm{M}_{\mathrm{ij}}$ representa as importações do setor i do país j (BRA);

$\mathrm{X}_{\mathrm{i}}$ representa as exportações totais do país $\mathrm{j}$ (BRA);

$\mathrm{M}_{\mathrm{i}}$ representa as importações totais do país j (BRA).

Segundo Fontenele, Melo e Rosa (2000), quando $\mathrm{TC}_{\mathrm{ij}}$ é superior à unidade $\left(\mathrm{TC}_{\mathrm{ij}}>1\right)$, identifica-se uma vantagem comparativa em termos de cobertura das exportações, ou seja, as exportações do setor i do país teriam uma dimensão maior se comparadas às importações do mesmo setor.

O segundo indicador é o Índice de Comércio Intraindústria (CII), o qual visa caracterizar o comércio do Brasil. Este índice consiste na utilização da exportação e importação simultânea de produtos do mesmo setor. Com o avanço e a difusão dos processos tecnológicos entre os países, muda-se a configuração do comércio internacional e o peso das vantagens comparativas (abundância de recursos). Apresenta-se como destaque o crescimento do comércio interindustrial. Conforme Appleyard, Field Jr. e Cobb (2010), diferentemente do comércio interindustrial, o comércio intraindústrial é explicado pelas economias de escala e pela diferenciação do produto.

O indicador setorial do comércio intraindustrial (CII) foi desenvolvido por Grubel e Lloyd (1975) e pode ser apresentado conforme a Equação 2:

$$
C I I=1-\frac{\sum_{i}\left|X_{i}-M_{i}\right|}{\sum_{i}\left(X_{i}+M_{i}\right)}
$$

em que:

$\mathrm{X}_{\mathrm{i}}$ representa as exportações do produto $\mathrm{i}$;

$\mathrm{M}_{\mathrm{i}}$ representa as importações do produto i. 
Quando o indicador CII se aproximar de zero, pode-se concluir que há comércio interindustrial, e, neste caso, o comércio é explicado pelas vantagens comparativas, ou seja, observa-se a presença de comércio entre produtos de diferentes setores do Brasil com os países parceiros. Esse evento pode ser observado ao constatar ocorrência de apenas importação ou apenas exportação do setor i (ou produto i). Por outro lado, quando CII for maior que 0,5 (CII>0,5), o comércio é caracterizado como sendo intraindustrial.

O padrão de comércio intraindustrial reflete uma pauta exportadora que, por sua vez, sucede uma estrutura produtiva dinamizada em progresso tecnológico e em economias de escala (ampliação de mercados). Todavia, a configuração interindustrial reflete o ordenamento entre os setores produtivos, baseado no uso da dotação de fatores e sob concorrência perfeita.

Esse arranjo explicativo das trocas comerciais pode indicar se determinado participante do comércio internacional alcançou ganhos de competitividade. Ressalta-se que, em meio à profusão de conceitos que foram dados a esse termo, entende-se, neste artigo, diante dos alcances e das limitações dos índices utilizados, que alcançar competitividade internacional significa atingir os maiores níveis de vantagem comparativa revelada e o padrão de inserção intraindustrial.

O terceiro indicador é o índice de Concentração Setorial das Exportações (ICS), também conhecido como coeficiente Gini-Hirchman, o qual quantifica a concentração das exportações de cada setor exportador i realizadas pelo país j (Brasil). O ICS é representado através da Equação 3:

$$
I C S_{i j}=\sqrt{\sum_{i}\left(\frac{X_{i j}}{X_{j}}\right)^{2}}
$$

em que:

$\mathrm{X}_{\mathrm{ij}}$ representa as exportações do setor i pelo país j (BRA); e,

$\mathrm{X}_{\mathrm{j}}$ representa as exportações totais do país $\mathrm{j}$ (BRA).

O ICS varia entre 0 e 1 , e, quanto mais próximo a 1 , mais concentradas serão as exportações em poucos setores e, por outro lado, quanto mais próximo de 0, mais diversificada será a composição da pauta de exportações. Pinheres e Ferratino (1997) apresentam abordagem alternativa para o cálculo das concentrações.

\subsection{Fonte de dados}

Os dados relativos às importações e exportações desagregadas para o setor florestal seguem o padrão da literatura empírica da área, conforme apresentados por Valverde et al. (2005a), com um maior grau de detalhamento do setor. Os códigos utilizados para cada categoria de produto, conforme a Nomenclatura Comum do $\mathrm{Mercosul}^{2}$, são descritos de acordo com a Tabela 2.

Tabela 2- Classificação do setor florestal e os códigos da NCM empregados

\begin{tabular}{l|l|l}
\hline Subdivisões do setor & Produtos & Códigos \\
\hline Indústria da borracha & Borracha e suas obras & 40 \\
\hline Madeira e mobiliário & Madeira, carvão vegetal e obras de madeira & 44 \\
& Cortiça e suas obras & 45
\end{tabular}

\footnotetext{
2 Para classificar as mercadorias, em 1996, o Brasil passou a utilizar a Nomenclatura Comum do Mercosul (NCM), a qual é utilizada pelos outros integrantes do bloco, baseado no Sistema Harmonizado de Designação e Codificação de Mercadorias (Capítulos SH) - (MDIC, 2015).
} 


\begin{tabular}{l|l|l} 
& Obras de espartaria ou cestaria & 46 \\
\hline Papel e gráfica & Pastas de madeira ou de outras matérias fibrosas celulósicas; & 47 \\
& papel ou cartão para reciclar & \\
& Papel e cartão; obras de pasta de celulose, de papel ou de cartão & 48 \\
& Livros, jornais, gravuras e outros produtos de indústrias gráficas & 49 \\
\hline
\end{tabular}

Fonte: Elaborada pelos autores $\begin{array}{ll}\text { Livros, jornais, gravuras e outros produtos de indústrias gráficas } & 49\end{array}$

O período de análise foi de 1999 a 2015, visto que o período inicial de análise representa o ano em que o Brasil adotou o regime de câmbio flutuante (VIANNA; BRUNO; MODENESI, 2010). O banco de dados para o cálculo destes indicadores foi obtido junto à Secretaria do Comércio Exterior (SECEX) do Ministério do Desenvolvimento, Indústria e Comércio do Brasil (MDIC), acessível através do Sistema de Análise de Informações do Comércio Exterior - ALICEWEB.

Desta forma, por meio desta classificação, têm-se a análise do padrão de especialização do comércio internacional do setor florestal brasileiro, a partir da próxima seção.

\section{ANÁLISE E DISCUSSÃO DOS RESULTADOS 4.1 TAXA DE COBERTURA DAS IMPORTAÇÕES (TC)}

Para analisar a taxa de cobertura das importações, deve-se levar em conta se a taxa de cobertura das importações é maior que a unidade (TC $>1$ ). Isso indica que, em determinado setor, as exportações brasileiras referentes ao setor florestal teriam uma dimensão maior se comparadas às importações do mesmo setor.

Diante de tais apontamentos, a Tabela 3 apresenta a taxa de cobertura das importações do setor florestal brasileiro. Ao analisar a respectiva Tabela, três setores emergem como sendo mais relevantes na pauta exportadora do setor florestal brasileiro, os quais apresentam maiores taxas de cobertura. Isso significa dizer que estes produtos apresentam uma maior vantagem comparativa em termos de cobertura das exportações. Tais produtos foram a) madeira, carvão vegetal e obras de madeira, com média 9,17; e b) pastas de madeira ou de outras matérias fibrosas celulósicas, papel ou cartão para reciclar, com média de 5,30 .

O setor que apresentou maior taxa de cobertura das importações foi o de madeira, carvão vegetal e obras de madeira, com média de 9,17. Esta taxa de exportação justifica-se em função da representatividade das florestas brasileiras, as quais cobrem aproximadamente 3.870 milhões de hectares do planeta, correspondendo a $30 \%$ de sua superfície, dos quais $95 \%$ são provenientes de florestas nativas e tão somente algo em torno de $5 \%$ de plantações florestais (IAC, 2016). 
Tabela 3 - Taxa de cobertura das importações do setor florestal brasileiro

\begin{tabular}{|c|c|c|c|c|c|c|c|}
\hline Produtos & $\begin{array}{c}\text { Borracha e suas } \\
\text { obras }\end{array}$ & $\begin{array}{c}\text { Madeira, carvão } \\
\text { vegetal e obras de } \\
\text { madeira }\end{array}$ & $\begin{array}{c}\text { Cortiça e suas } \\
\text { obras }\end{array}$ & $\begin{array}{c}\text { Obras de } \\
\text { espartaria ou } \\
\text { cestaria }\end{array}$ & $\begin{array}{l}\text { Pastas de madeira } \\
\text { ou de outras } \\
\text { matérias fibrosas } \\
\text { celulósicas; papel } \\
\text { ou cartão para } \\
\text { reciclar } \\
\end{array}$ & $\begin{array}{l}\text { Papel e cartão; } \\
\text { obras de pasta de } \\
\text { celulose, de papel } \\
\text { ou de cartão }\end{array}$ & $\begin{array}{l}\text { Livros, jornais, } \\
\text { gravuras e outros } \\
\text { produtos de } \\
\text { indústrias } \\
\text { gráficas }\end{array}$ \\
\hline 1999 & 0,40 & 9,55 & 0,06 & 0,02 & 2,59 & 0,74 & 0,06 \\
\hline 2000 & 0,36 & 8,62 & 0,07 & 0,02 & 2,76 & 0,72 & 0,05 \\
\hline 2001 & 0,33 & 10,66 & 0,05 & 0,02 & 2,78 & 0,87 & 0,06 \\
\hline 2002 & 0,30 & 13,09 & 0,09 & 0,02 & 2,37 & 0,88 & 0,08 \\
\hline 2003 & 0,27 & 9,47 & 0,11 & 0,45 & 2,96 & 0,94 & 0,12 \\
\hline 2004 & 0,25 & 10,95 & 0,09 & 0,28 & 2,52 & 0,80 & 0,17 \\
\hline 2005 & 0,30 & 12,65 & 0,10 & 0,02 & 3,33 & 0,69 & 0,18 \\
\hline 2006 & 0,31 & 10,18 & 0,11 & 0,02 & 4,48 & 0,64 & 0,18 \\
\hline 2007 & 0,32 & 9,27 & 0,10 & 0,01 & 5,16 & 0,75 & 0,14 \\
\hline 2008 & 0,31 & 7,57 & 0,12 & 0,02 & 7,04 & 0,82 & 0,15 \\
\hline 2009 & 0,33 & 6,98 & 0,12 & 0,01 & 6,19 & 0,87 & 0,12 \\
\hline 2010 & 0,30 & 8,18 & 0,15 & 0,01 & 7,29 & 0,88 & 0,14 \\
\hline 2011 & 0,33 & 7,01 & 0,17 & 0,01 & 8,53 & 0,95 & 0,15 \\
\hline 2012 & 0,34 & 7,03 & 0,17 & 0,02 & 8,21 & 0,89 & 0,14 \\
\hline 2013 & 0,27 & 8,67 & 0,16 & 0,01 & 9,37 & 0,93 & 0,09 \\
\hline 2014 & 0,26 & 8,24 & 0,13 & 0,01 & 8,10 & 0,84 & 0,09 \\
\hline 2015 & 0,22 & 7,73 & 0,09 & 0,01 & 6,49 & 0,94 & 0,08 \\
\hline
\end{tabular}

Fonte: Elaboração própria a partir dos dados do Sistema Alice Web 
As florestas tropicais representam $47 \%$ e as subtropicais, em torno de $9 \%$ da cobertura florestal do mundo, enquanto as florestas temperadas e boreais representam $44 \%$. O Brasil possui a segunda maior cobertura florestal do planeta, que equivale a 14,5\% da superfície florestal mundial, sendo superado apenas pela federação da Rússia (ORGANIZAÇÕES DAS NAÇOES UNIDAS PARA AGRICULTURA E ALIMENTAÇÃO - FAO, 2010).

Dos 845,7 milhões de hectares do território nacional, aproximadamente $64,3 \%$, ou 544 milhões de ha são cobertos por florestas nativas e 5 milhões de florestas plantadas, as quais, somadas, proporcionavam ao país, em 2000, 64,3\% de cobertura florestal. Dessa forma, do total de florestas nativas, 2/3 são formados pela floresta Amazônica e o restante pelo Cerrado (MINISTÉRIO DO MEIO AMBIENTE- MMA, 2011). Essa ampla extensão de cobertura florestal impõe ao Brasil uma posição estratégica nas questões ambientais mundiais, além de dotá-lo de um grande potencial produtivo de produtos madeireiros e não madeireiros.

Com relação ao carvão, observa-se que os principais produtores no país estão localizados no estado de Minas Gerais, Pará e Maranhão, Mato Grosso do Sul e Espírito Santo. Destacam-se também pelo consumo de carvão vegetal para suprir as siderúrgicas instaladas nessas regiões (SOUZA ET AL, 2010). A região do Cerrado concentra grande parte da produção de carvão vegetal, o que pode ser explicado pela concentração de reservas de minérios no estado de Minas Gerais. Nesse estado está situado o quadrilátero ferrífero, região fundamental para o desempenho da balança comercial brasileira, que compreende os municípios de Belo Horizonte, Ouro Preto, Santa Bárbara, Itabira e Mariana, e é responsável por cerca de $60 \%$ da extração de minério de ferro (IAC, 2016).

Já o setor de matérias fibrosas celulósicas, papel e pastas de celulose, de papel e de cartão apresentam-se em segundo e terceiro lugar, respectivamente, na representatividade das exportações brasileiras. Essa competitividade pode ser explicada por vários fatores, dentre eles as políticas do Banco Nacional de Desenvolvimento Econômico e Social - BNDES que vem financiando o segmento de papel e celulose desde a década de 1960, o baixo custo de produção e a grande utilização de papel no mundo todo. É favorecida também pela alta produtividade dos reflorestamentos e pelas condições climáticas em relação aos outros países (IPEF, 2016).

\section{2 ÍNDICE DE COMÉRCIO INTRAINDÚSTRIA (CII)}

O índice de comércio intraindústria representa o padrão comercial dentro de um mesmo setor, e, quando for maior que 0,5 , indica comércio intraindustrial. Caso contrário, se for menor que 0,5 , é considerado interindustrial. Dos 7 setores analisados, apenas 2 indicaram haver comércio intraindústria ao longo de todo o período analisado, de acordo com a Tabela 4. Tais setores foram: a) borracha e suas obras, com média de 0,84 ; e b) papel e cartão; obras de pasta de celulose, de papel ou de cartão, com média de 0,68 , do período analisado.

De acordo com a Tabela 4, observa-se que o principal setor que apresenta comércio intraindustrial, ou seja, em que o comércio se baseia na diferenciação de produto, em economias de escala e concorrência monopolística, é o setor de borrachas e suas obras. O Brasil produz apenas $35 \%$ da demanda nacional por borracha natural. Atualmente a demanda é muito maior que a produção nacional, o que requer mais avanços da heveicultura, já que só abastece $35 \%$ da necessidade total. (IAC, 2016). Dessa forma, fica explícito que as importações brasileiras no setor de borracha, possuindo como principal estado produtor São Paulo, com cerca de $54 \%$ da produção nacional, não é suficiente para atender a demanda, necessitando de mais investimentos neste segmento (IPEF, 2016). Por fim, observa-se uma lacuna do setor, onde o país é deficitário, e necessita de maiores investimento para instigar mais a competitividade, propiciando a sua exportação.

O segundo setor que apresenta maior comércio intraindustrial é o papel e cartão; obras de pasta de celulose, de papel ou de cartão. O Brasil é o maior produtor mundial de celulose de fibra curta, pois o clima brasileiro favorece o plantio de eucalipto, ao passo que, nos demais países produtores, a produção de celulose de fibra longa é maior, pois o clima favorece mais as florestas de 
pinus. A fibra curta tem maior capacidade absorvente, destina-se a produtos menos rígidos como papel para impressão e para escrever, papéis tissue (higiênicos); a fibra longa é mais resistente e utilizada na fabricação de embalagens. Já as pastas de alto rendimento são utilizadas na produção de papel jornal e podem ser misturadas com fibra longa ou curta para dar maior resistência; a celulose solúvel - celulose que não tem as mesmas utilizações da celulose comum - fibras têxteis (viscose), são utilizados na fabricação de celofane, filtros de cigarro e para salsicha (DEPARTAMENTO DE PESQUISAS E ESTUDOS ECONÔMICOS - DEPEC, 2016). 
Tabela 4 - Índice de Comércio Intraindústria individual para o setor florestal brasileiro

\begin{tabular}{|c|c|c|c|c|c|c|c|c|c|c|c|c|c|c|c|c|c|}
\hline Produtos/ano & 1999 & 2000 & 2001 & 2002 & 2003 & 2004 & 2005 & 2006 & 2007 & 2008 & 2009 & 2010 & 2011 & 2012 & 2013 & 2014 & 2015 \\
\hline Borracha e suas obras & 0,99 & 0,94 & 0,91 & 0,95 & 0,99 & 0,95 & 0,95 & 0,94 & 0,92 & 0,80 & 0,84 & 0,69 & 0,68 & 0,70 & 0,61 & 0,64 & 0,71 \\
\hline $\begin{array}{l}\text { Madeira, carvão vegetal e } \\
\text { obras de madeira }\end{array}$ & 0,08 & 0,09 & 0,07 & 0,05 & 0,05 & 0,05 & 0,05 & 0,07 & 0,08 & 0,12 & 0,12 & 0,13 & 0,17 & 0,16 & 0,13 & 0,13 & 0,10 \\
\hline Cortiça e suas obras & 0,25 & 0,28 & 0,21 & 0,43 & $\mathbf{0 , 5 7}$ & 0,47 & 0,47 & 0,48 & 0,43 & 0,40 & 0,43 & 0,42 & 0,41 & 0,43 & 0,40 & 0,38 & 0,36 \\
\hline Obras de espartaria ou cestaria & 0,09 & 0,09 & 0,08 & 0,09 & 0,74 & $\mathbf{0 , 9 9}$ & 0,13 & 0,09 & 0,07 & 0,07 & 0,05 & 0,03 & 0,04 & 0,07 & 0,05 & 0,04 & 0,04 \\
\hline $\begin{array}{l}\text { Pastas de madeira ou de outras } \\
\text { matérias fibrosas celulósicas; } \\
\text { papel ou cartão para reciclar }\end{array}$ & 0,26 & 0,26 & 0,24 & 0,25 & 0,16 & 0,20 & 0,18 & 0,15 & 0,13 & 0,13 & 0,14 & 0,14 & 0,14 & 0,14 & 0,13 & 0,13 & 0,11 \\
\hline $\begin{array}{l}\text { Papel e cartão; obras de pasta } \\
\text { de celulose, de papel ou de } \\
\text { cartão }\end{array}$ & 0,69 & 0,73 & 0,61 & 0,55 & 0,44 & 0,51 & 0,65 & 0,71 & 0,66 & 0,73 & 0,69 & 0,78 & 0,81 & 0,82 & 0,80 & 0,80 & 0,59 \\
\hline $\begin{array}{l}\text { Livros, jornais, gravuras e } \\
\text { outros produtos de indústrias } \\
\text { gráficas }\end{array}$ & 0,25 & 0,24 & 0,25 & 0,39 & 0,64 & $\mathbf{0 , 7 7}$ & $\mathbf{0 , 6 9}$ & 0,68 & $\mathbf{0 , 5 5}$ & 0,48 & 0,41 & 0,40 & 0,38 & 0,37 & 0,25 & 0,29 & 0,34 \\
\hline
\end{tabular}

Fonte: Elaboração própria a partir dos dados do Sistema Alice Web 
A Tabela 4 evidencia ainda que, no período de análise, apenas no ano de 2003, o setor de cortiças e suas obras destacou-se como comércio de intraindústria, com indicador de 0,57. Já o setor de obras de espartaria ou cestaria apresentou apenas nos anos de 2003 e 2004, indicadores de 0,74 e 0,99, respectivamente, evidenciando comércio de intraindústria. O setor de livros, jornais, gravuras e outros produtos de indústrias gráficas apresentou comércio de intraindústria em 2003 até 2007, com indicadores de 0,$64 ; 0,77 ; 0,69 ; 0,68 ; 0,55$, respectivamente. Por fim, o setor de papel e cartão; obras de pasta de celulose, de papel ou de cartão, no período de análise, apresentou comércio intraindústria, na maior parte do período de análise, oscilando apenas no ano de 2003, com indicador de 0,44, no qual apresentou comércio de interindustrial.

A análise do padrão de especialização do comércio florestal brasileiro pode ser verificada também de forma agregada, de acordo com a Tabela 5, apresentando média de 0,46 do período analisado.

Tabela 5 - Índice de comércio intraindústria - CII agregado para o setor florestal brasileiro

\begin{tabular}{lc}
\hline Ano & CII \\
\hline 1999 & 0,49 \\
2000 & 0,49 \\
2001 & 0,46 \\
2002 & 0,44 \\
2003 & 0,41 \\
2004 & 0,40 \\
2005 & 0,46 \\
2006 & 0,47 \\
2007 & 0,48 \\
2008 & 0,48 \\
2009 & 0,49 \\
2010 & 0,48 \\
2011 & 0,50 \\
2012 & 0,50 \\
2013 & 0,44 \\
2014 & 0,43 \\
2015 & 0,38 \\
\hline
\end{tabular}

Fonte: Elaboração própria a partir dos dados do Sistema Alice Web.

Para análise do índice de comércio intraindústria agregado, os resultados indicaram comércio interindustrial, em que o setor florestal brasileiro variou em torno de 12\% (menor 38\% em 2015 e maior 50\% em 2011 e 2012) entre 1999 e 2015. Isso permitiu concluir que, em média, o Brasil apresenta especialização nos setores florestais com vantagens comparativas.

\section{3 ÍNDICE DE CONCENTRAÇÃO SETORIAL DAS EXPORTAÇÕES (ICS)}

A abertura comercial brasileira se intensificou na primeira metade da década de 1990. Assim, o aumento da competitividade internacional impôs pressão sobre a 
estrutura produtiva, por um lado, pela presença dos produtos importados no mercado interno e, por outro lado, pela necessidade da produção de produtos competitivos internacionalmente (DINIZ, 2002).

Em relação ao índice de concentração setorial das exportações, a análise deve partir dos resultados, uma vez que, quanto mais próximo a 0 , mais diversificada será a composição da pauta exportadora. Por sua vez, quanto mais próximo a 1, mais concentradas são as exportações em poucos setores. A Tabela 6 apresenta os resultados do ICS para o setor florestal brasileiro.

Tabela 6 - Índice de Concentração Setorial das exportações para o setor florestal brasileiro

\begin{tabular}{ll}
\hline Ano & ICS \\
\hline 1999 & 0,51 \\
2000 & 0,52 \\
2001 & 0,51 \\
2002 & 0,52 \\
2003 & 0,52 \\
2004 & 0,54 \\
2005 & 0,53 \\
2006 & 0,52 \\
2007 & 0,51 \\
2008 & 0,51 \\
2009 & 0,52 \\
2010 & 0,54 \\
2011 & 0,53 \\
2012 & 0,53 \\
2013 & 0,55 \\
2014 & 0,55 \\
2015 & 0,56 \\
\hline
\end{tabular}

Fonte: Elaboração própria a partir dos dados do Sistema Alice Web

Após apresentar a Tabela 6, é possível considerar que o Brasil apresenta uma pauta de exportações em relação ao setor florestal altamente uniforme, com a média do indicador de 0,52, e no período analisado, oscilando entre 0,51 e 0,56. Tais resultados mostram que as exportações do setor florestal brasileiro não são nem concentradas nem desconcentradas e esse resultado é reflexo do padrão interindustrial comercial. No período de análise, o setor que mais se destacou nas exportações foi o da indústria de papel e gráfica, a qual contribuiu de forma relevante para o desenvolvimento do país, devido muito ao baixo custo de produção e à grande utilização de papel no mundo todo.

\section{CONSIDERAÇÕES FINAIS}

Este estudo dedicou-se a analisar o setor florestal brasileiro do ponto de vista das relações entre as exportações e as importações. Dessa forma, a análise centrou-se nos setores produtivos mais dinâmicos do setor florestal, os quais detêm parcela significativa na composição da pauta exportadora brasileira.

Os apontamentos deste trabalho permitiram destacar as peculiaridades setoriais da competitividade do país, mostrando o grau de competitividade dos setores florestais analisados em relação ao mercado internacional.

No atual cenário socioeconômico, político e ambiental brasileiro, muitos são os desafios a serem enfrentados pelas empresas florestais. A estrutura organizacional do setor florestal é de gestão descentralizada, e voltada, prioritariamente, à questão do meio ambiente. 
A produção florestal é entendida como parte da gestão ambiental e tais fatos, seguramente, diminuem a competitividade das empresas do setor. Assim, a potencialidade do recurso florestal brasileiro não tem sido utilizada de maneira a garantir respostas sociais e econômicas satisfatórias. Vale ressaltar que, embora tais respostas possuam expressividade, estão, com certeza, muito aquém do potencial existente, podendo crescer significativamente.

A partir da análise dos diversos indicadores, dois produtos emergem como sendo mais relevantes na pauta exportadora do setor florestal brasileiro. Tais produtos foram: a) madeira, carvão vegetal e obras de madeira; e b) pastas de madeira ou de outras matérias fibrosas celulósicas, papel ou cartão para reciclar. Além disso, dos 7 setores analisados, apenas 2 indicaram haver comércio intraindústria ao longo de todo o período analisado. Tais setores foram: a) borracha e suas obras; e b) papel e cartão; obras de pasta de celulose, de papel ou de cartão. Por fim, foi possível considerar ainda que o Brasil apresenta uma pauta de exportações em relação ao setor florestal altamente uniforme, com a média do indicador de 0,52. Estes resultados mostraram que as exportações do setor florestal brasileiro não são nem concentradas nem desconcentradas e esse resultado é reflexo do padrão interindustrial comercial.

Como limitação do trabalho, tem-se que os índices utilizados são estáticos, pois não compreendem alterações em fatores econômicos, como barreiras comerciais, tratados de livre comércio, variações no consumo interno, entre outros. Além disso, ressalta-se a escassez de pesquisas no setor florestal para corroborar os resultados encontrados. Nesse sentido, sugere-se, para pesquisas futuras, a utilização de Modelos de Equilíbrio Geral Dinâmicos com o intuito de identificar os impactos de políticas econômicas no setor florestal brasileiro.

\title{
SPECIALIZATION PATTERN OF INTERNATIONAL TRADE IN THE BRAZILIAN FOREST SECTOR (1999-2015)
}

\begin{abstract}
:
This study aimed to analyze the specialization pattern of international trade in the Brazilian forest sector, identifying the most dynamic productive sectors in the period between 1999 and 2015. In this sense, the Import Coverage Ratio (ICR) was calculated, as well as the Intraindustry Trade Index (IIT) and the Sectoral Concentration of Exports (ICS). The data were obtained from the System of Foreign Trade Information Analysis (Alice Web). The results indicated that Brazil has comparative advantages in the sectors of wood, charcoal, wood derivatives and pulp of wood or other fibrous cellulosic material, paper or paperboard for recycling. Most sectors that belong to the forest industry present inter-industry trade, except for rubber and its derivatives, paper and paperboard, and items that derive from celulose pulp, paper or paperboard. In addition, the Brazilian forest sector presents a uniform concentration pattern.
\end{abstract}

Keywords: Exports; Brazil; Forest Sector.

\section{REFERÊNCIAS}

ASSOCIAÇÃO BRASILEIRA DE PRODUTORES DE FLORESTAS PLANTADAS ABRAF. Anuário Estatístico, 2013.

Disponível em: <http://www.bibliotecaflorestal.ufv.br〉. Acesso em: 06 set, 2016.

APPLEYARD, D.; FIELD JR., A, J.; COBB, S. L. Economia Internacional. 6 ed. Porto Alegre: McGraw Hill, 2010. 
CARVALHO, R.M.M.A.; SOARES, T.S.; VALVERDE, S.R. Caracterização do setor florestal: uma abordagem comparativa com outros setores da economia. Ciência Florestal, v. 15, n. 1, 2005.

CRUVINEL, P. E. O agronegócio e oportunidades para o desenvolvimento sustentável no Brasil. Empresa Brasileira de Pesquisa Agropecuária, Documentos 44, set. 2009.

DEPARTAMENTO DE PESQUISAS E ESTUDOS ECONÔMICOS - DEPEC. Documento, 2016. Disponível em: 〈http: //economiaemdia.com.br〉. Acesso em: 20 dez, 2016.

DINIZ, C. C. Unidade e fragmentação: a questão regional no Brasil. São Paulo: Perspectiva, 2002.

ESTUDO SETORIAL: INDÚSTRIA DE MADEIRA PROCESSADA MECANICAMENTE. Documento ABIMCI: Estudo setorial 2009 ano calendário 2008. Brasília, 2014. Disponível em: 〈http: //www.abimci.com.br>. Acesso em: 06 set, 2016.

ORGANIZAÇÕES DAS NAÇOES UNIDAS PARA AGRICULTURA E ALIMENTAÇÃO - FAO. Documentos, 2010. Disponível em:

<http://www.fao.org/brasil/pt/. Acesso em: 15 out, 2016.

FONTENELE, A. M. de C.; MELO, M. C. P.; ROSA, A. L. T. A Indústria Nordestina Sob a Ótica da Competitividade Sistêmica. Fortaleza: EUFC/SUDENE/ACEP, 2000.

GRUBEL, H.; LLOYD, P. Intra-Industry Trade: the theory and the measurement of international trade in differentiated products. London: Macmillan, 1975.

INSTITUTO DE PESQUISAS E ESTUDOS FLORESTAIS - IPEF. Documentos florestais. Disponível em:<http://www.ipef.br>. Acesso em: 06 set, 2016.

INSTITUTO AGRONÔMICO DE CAMPINAS - IAC. Relatórios IAC exercício 2010. Disponível em: http://www.iac.sp.gov.br. Acesso em: 10 set, 2016.

JUVENAL, T. L.; MATTOS, R. L. G. O setor florestal no Brasil e a importância do reflorestamento. BNDES Setorial, n. 16, p. 3-30, set., 2002.

LENTINI, M.; PEREIRA, D.; CELENTANO, D.; PEREIRA, R. Fatos florestais da Amazônia. Belém: Instituto do Homem e Meio Ambiente da Amazônia, 2005.

MINISTÉRIO DO DESENVOLIMENTO DA INDÚSTRIA E COMERCIO EXTERIOR - MDIC. Secretaria de Comércio Exterior (SECEX). Disponível em: <http://www.mdic.gov.br/sitio/>. Acesso em: 31 jan. 2015.

MINISTÉRIO DO MEIO AMBIENTE, 2011- MMA. Assuntos: educação ambiental. Disponível em: <http://www.mma.gov.br>. Acesso em: 05 dez. 2016.

NOCE, R.; CARVALHO, R. M. A. M.; SOARES, T. S.; SILVA, M. L. Desempenho do Brasil nas exportações de madeira serrada. Revista Árvore, v.27, n.5, 2003. 
NOCE, R.; SILVA, M. L.CARVALHO, R. M. A. M.; SOARES, T. S. Concentração das exportações no mercado internacional de madeira serrada. Revista Árvore, v.29, n.3, 2005.

PETRAUSKI, S.M.F.C.; MARQUES, G.M.; SILVA, M.L.; CORDEIRO, S.A.; SOARES, N.S. Competitividade do Brasil no comércio internacional de madeira serrada. Revista Cerne, Lavras, v. 18, n. 1, p. 99-104, jan./mar. 2012.

PINHERES, G. S.; FERRANTINO, M. Export diversification and structural dynamics in the growth process: the case of Chile, Journal of Development Economics, v. 52, n. 2, Amsterdam, Elsevier Science, abr. 1997.

SISTEMA DE ANÁLISE DAS INFORMAÇÕES DE COMÉRCIO EXTERIOR ALICE WEB. Consultas. Disponível em: <http://aliceweb.mdic.gov.br/>. Acesso em: 09 out. 2016.

SOUZA, E. P.; SOARES, N. S.; SILVA, M. L.; VALVERDE, R. S. Desempenho do setor florestal para a economia brasileira: uma abordagem da matriz insumo-produto. Revista Árvore, v.34, n.6, 2010.

VALVERDE, R. S.; OLIVEIRA, G. G.; SOARES, T. S.; CARVALHO, R. M. A. M. Participação do setor florestal nos indicadores socioeconômicos do estado do Espírito Santo. Revista Árvore, v.29, n.1, p.105-113, 2005a.

VALVERDE, R. S.; OLIVEIRA, G. G.; CARVALHO, R. M. A. M.; SOARES, T. S. Efeitos multiplicadores do setor florestal na economia capixaba. Revista Árvore, v.29, n.1, 2005b.

VALVERDE, R. S.; SOARES, N. S.; SILVA, M. L. Desempenho das exportações brasileiras de celulose. Revista Árvore, v.30, n.6, 2006.

VIANNA, S. T. W.; BRUNO, M. A. P.; MODENESI, A. M. Macroeconomia para o Desenvolvimento: crescimento, estabilidade e emprego. 4. ed. Rio de Janeiro: IPEA, 2010. 397 p. 